\title{
PATHS OF AXONS IN THE VISUAL SYSTEM OF PERCIFORM FISH AND IMPLICATONS OF THESE PATHS FOR RULES GOVERNING AXONAL GROWTH ${ }^{1}$
}

\author{
ANNE C. RUSOFF \\ Department of Physiological Sciences, Oklahoma State University, Stillwater, Oklahoma 74078 \\ Received March 30, 1983; Revised December 14, 1983; Accepted December 14, 1983
}

\begin{abstract}
The optic nerve of many perciform fish is ribbon-shaped, and axons from ganglion cells in specific parts of the retina are consistently found in specific places in this ribbon. I utilized this organization to fill selected groups of axons with horseradish peroxidase. I then traced these groups of axons through the nerve and across the tectum to their terminal arbors. The paths of the axons suggest that axons use a number of different mechanisms to guide them to their correct terminal sites. At some points they appear simply to grow along the surface created by earlier axons, but at other points they seem to be using cues more complex than simple mechanical guidance.

In addition, I have demonstrated that for every anulus of ganglion cells on the retina there is an anulus of terminal arbors on the tectum. With time the terminals in a given anulus must move caudally to keep the retinotopic map centered on the tectum while the tectum continues growing nonsymmetrically. I have shown both that the anuli of terminals do remain roughly centered on the tectum and that the predicted pattern of terminal movement is visible on the tecta of perciform fish.
\end{abstract}

Many perciform fish, an order which includes such common fish as perch, sunfish, and cichlids (Greenwood et al., 1966), have a ribbon-shaped optic nerve (Studnicka, 1897). If the connective tissue sheath around the optic nerve is severed, the ribbon can be flattened out into a single sheet which connects the retina to the tectum (Scholes, 1979). Scholes showed that the axons of the retinal ganglion cells are grouped in this sheet in a very precise pattern. The oldest axons, that is, those which were the first to grow out and which arise from cells in the most central part of the retina, form a band along one edge of the sheet, and the youngest axons, those from cells at the peripheral margin of the retina, form a band at the opposite edge of the sheet. The remaining axons are arranged between these two bands such that there is a gradient of age across the sheet (Scholes, 1979). In fish which continue to grow throughout their life, new neurons are added to the nervous system for a large part of life, often for several years (Müller, 1952; Johns, 1977, 1981; Kock and Reuter, 1978;

I This work was supported by Research Grants EY-03333 and EY03666. I thank Dr. Stephen S. Easter, Jr. in whose laboratory this work was begun for helpful discussions and Drs. Easter, Claudia A. O. Stuermer, Pamela A. Raymond, and Mark W. Dubin for comments on the paper.
Easter et al., 1979). Therefore, the oldest axons in the optic nerve are from cells which were born before the fish hatched from the egg, and the youngest axons are from cells which were born as much as several years later. The fish which I used for this study all were considerably below the maximum size attained by these species and presumably were still growing; thus, the youngest axons in their optic nerves had not yet reached the tectum.

Since in the retina of juvenile and adult fish new ganglion cells are continually added at all points around the peripheral margin (Johns, 1977; Meyer, 1978), Scholes's result predicts that each age-related band in the nerve contains the axons from the ganglion cells in a given anulus of retina. I have verified and utilized this organization to visualize axons from discrete anuli of retinal ganglion cells, using injections of the enzyme horseradish peroxidase (HRP) into the optic nerve. The enzyme was transported through the axons both to their terminals in the tectum and to their sites of origin on the retina.

This technique allows anatomical demonstration of the map of the retina on the tectum. Since the smallest of the species of fish which I used grows to be at least 10 $\mathrm{cm}$ long, I was able to study recent developmental events in fish which were large enough so that I was able to 
make selective injections into their optic nerves. I report here that for every anulus of filled ganglion cells on the retina there is a corresponding anulus of filled terminals on the tectum. The axon terminals in various anuli are illustrated, and their positions are compared with the positions of their axons on the tectal surface; these comparisons confirm the model of Easter and Stuermer (1982) which describes the shifting of axonal terminals after nonsymmetrical growth of the tectum. Furthermore, I show here that axons which terminate in the same region need not always travel together at all points across the tectum, strongly suggesting that axons use cues in addition to mechanical guidance to find target sites. Preliminary results of these experiments have been presented (Rusoff, 1980).

\section{Materials and Methods}

Two species of the order Perciformes were used: the pink kissing gourami (Helostoma temmincki, suborder Anabantoidei, family Helostomatidae) and the green sunfish (Lepomis cyanellus, suborder Percoidei, family Centrarchidae). These species were chosen because they were available from local dealers and were relatively easy to maintain. Twenty pink kissing gouramis (standard length, 4.9 to $10.2 \mathrm{~cm}$ ) and three sunfish (standard length, 9.8 to $12.0 \mathrm{~cm}$ ) were used. (Standard length is measured from the tip of the nose to the base of the tail.)

Prior to application of the IIRP, each fish was anesthetized with $0.1 \%$ MS222 (tricaine methanesulfonate). The skin covering the posterior portion of the orbit was removed and the eye rolled inward, bringing the orbital portion of the optic nerve into view. The nerve was then damaged either by inserting a \#0 insect pin into it or by cutting it, and a piece of Gelfoam (Upjohn) soaked in $30 \%$ HRP (Miles) was inserted into the damaged region. (Both optic nerves were used in most fish.) The fish was revived and returned to an aquarium kept at $15^{\circ} \mathrm{C}$ for 1 to 4 days. The fish was then reanesthetized and perfused via the heart with a phosphate-buffered glucose solution containing $1 \%$ sodium nitrite (a vasodilator), in an attempt to remove the red blood cells from the vessels in the tectum. The fish was then killed, and the eyes, nerves, and tecta were removed as a unit and immersed in $2 \%$ glutaraldehyde in phosphate buffer. The outer coats of each eye were removed immediately after immersion; otherwise, the fixative caused the pigmented epithelium to adhere permanently to the retina. After fixation, the nerve was cut free at the optic nerve head and at the rostral lip of the tectum; the retina and tectum were mounted whole on a freshly gelatinized slide, and the optic nerve was embedded in gelatin and cut into 40- to $50-\mu \mathrm{m}$ thick cross- or longitudinal sections on a cryostat or Vibratome. All tissue was then soaked in a mixture of $10 \%$ cobaltous chloride and $1 \%$ dimethylsulfoxide in distilled water for $20 \mathrm{~min}$, washed in water, incubated in a mixture of $o$-dianisidine $(45 \mathrm{mg} / 150 \mathrm{ml})$ and $1 \%$ dimethylsulfoxide in phosphate buffer (Fisher, $\mathrm{pH} 7.0$ ) for $20 \mathrm{~min}$, and then reacted an additional $20 \mathrm{~min}$ in the $o$ dianisidine mixture plus hydrogen peroxide $(5 \mathrm{ml}$ of $1 \%$ hydrogen peroxide $/ 150 \mathrm{ml}$ ) to reveal the presence of HRP (Easter et al., 1981).

\section{Results}

A tracing of a cross-section of an optic nerve from one kissing gourami is shown in Figure $1 A$. In this case the connective tissue sheath around the nerve was not removed before an insect pin coated with HRP was passed through the width of the nerve twice. As a result, three bands in the ribbon of the nerve (indicated by the dots) are filled with HRP reaction product. Two of the bands are prominent; the third-the middle one-is smaller, less densely stained, and does not fully cross the width of the nerve. If, as suggested by Scholes's model, each band of axons came from an anulus of ganglion cells in the retina, there should be three anuli of cells which contain HRP reaction product on the retina which was attached to this nerve. A tracing of a sector of the retina is shown in Figure $1 C$, and a photomosaic of the central portion of this sector is shown in Figure $1 D$. Each of the two arrows indicates a band with many ganglion cells filled with HRP reaction product. Each arrow originates from the corresponding band on the tracing of the retina. The small arrowheads indicate cells in a third, much more faintly staining band. In the complete flat mount, one can see that each of the two darker bands continues around the circumference of the retina to form an anulus and the lighter band continues part of the way around the retina.

A cross-section from the optic nerve of a second kissing gourami is shown in Figure 2A. In this case the insect pin coated with HRP was passed through one edge of the nerve, resulting in one darkly filled band of axons in the optic nerve (arrowhead). Apparently while making the injection the two edges of the optic nerve were also damaged, and a few axons at each edge also took up the HRP (small arrows). A photomosaic of a sector of the retina which was attached to this nerve is shown in Figure $3 A$, and a higher magnification of the peripheral margin of this retina is shown in Figure $3 B$. The arrows indicate one wide band of ganglion cells filled with HRP reaction product about $500 \mu \mathrm{m}$ from the retinal margin and a very narrow band of filled ganglion cells near the margin. Both bands continue around the circumference of the retina to form anuli and are related to the bands of filled axons indicated by the arrowhead and by the upper small arrow, respectively, in the optic nerve in Figure $2 A$. A small cluster of filled ganglion cells near the optic disc on this retina (not shown) is the source of the filled axons indicated by the lower small arrow in Figure $2 A$. Thus, in these two preparations, for each band of axons filled with HRP reaction product in the nerve, there is a corresponding band of ganglion cells filled in the retina.

The positions of filled ganglion cells were determined on 18 retinas which were relatively free of adhering pigmented epithelium; in all cases, from the position of either the filled ganglion cells on the retina or the filled axons in the optic nerve, using Scholes's model (1979), one could correctly predict the distribution of the other. That is, axons from an anulus of retinal ganglion cells were together in a band in the optic nerve, and these bands were arrayed across the nerve chronotopically with youngest at one side and oldest at the other. I am 

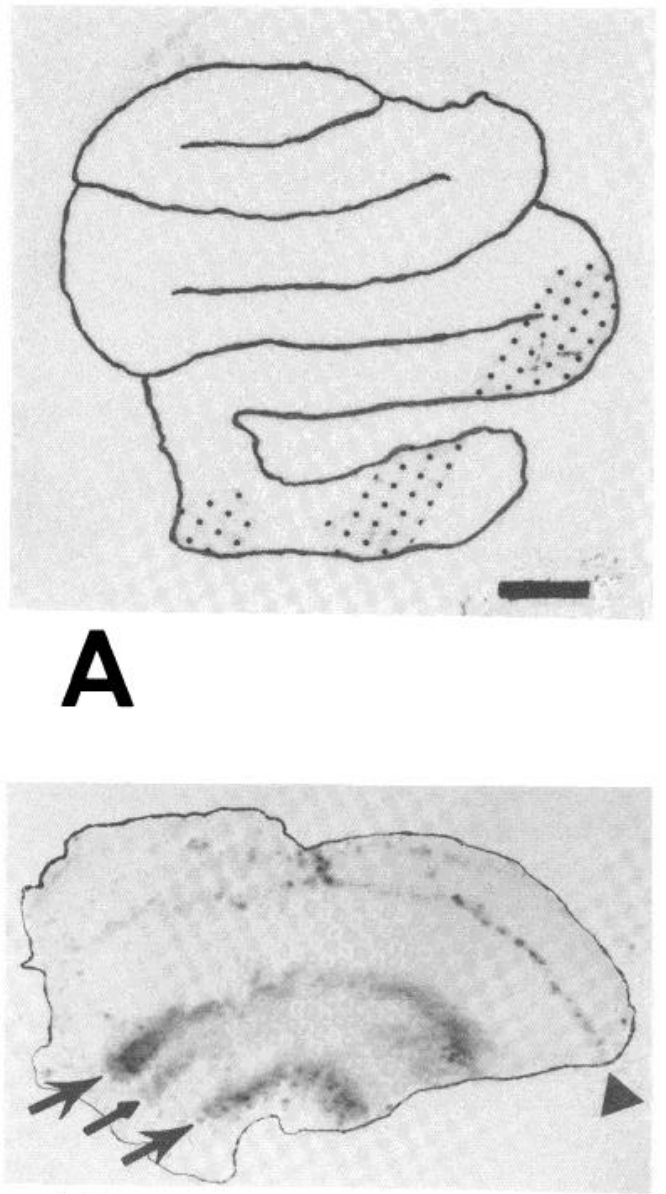

B

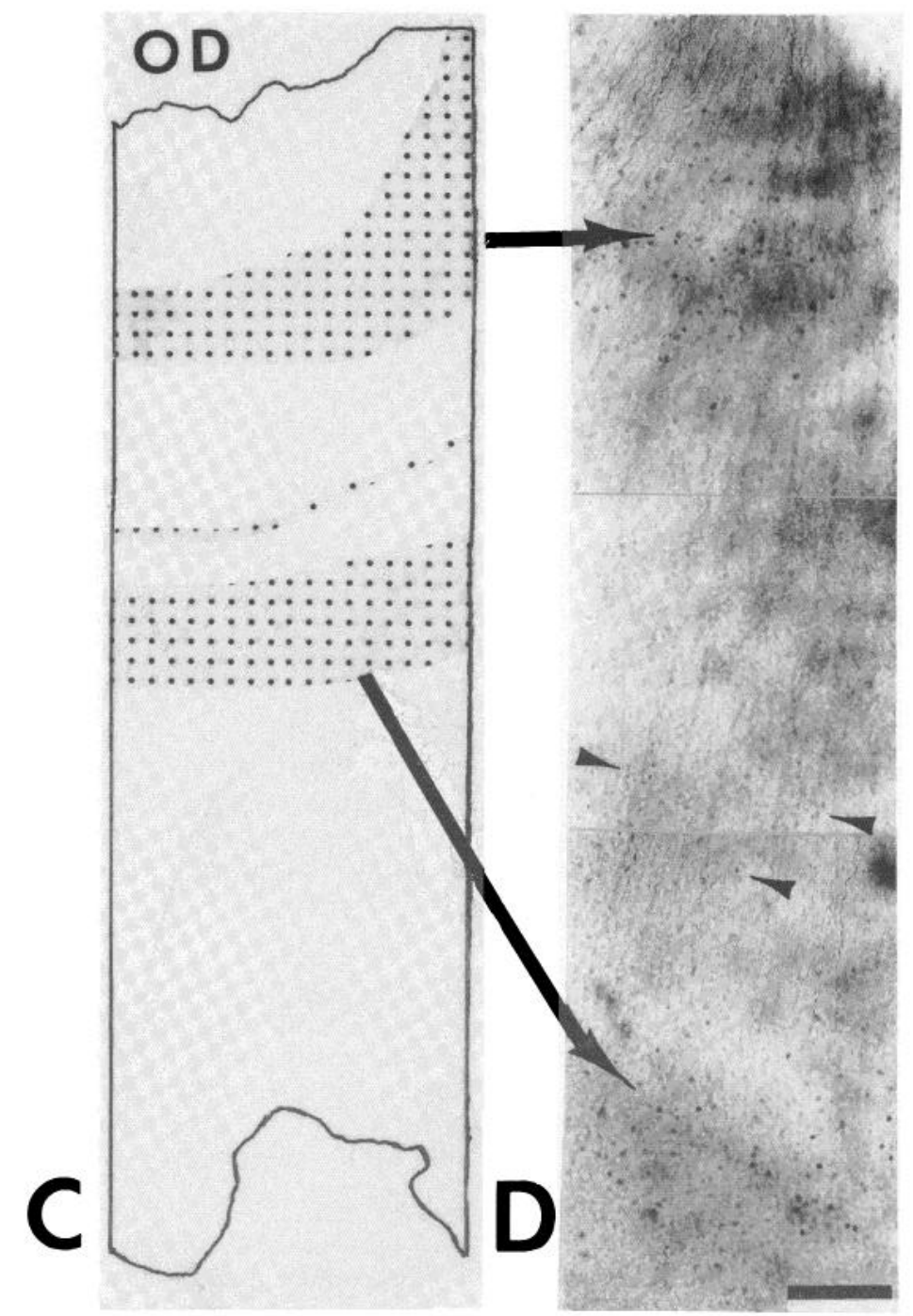

Figure 1. The optic nerve, tract, and retina from a pink kissing gourami which received two injections of HRP into the nerve. $A$, Tracing of a cross-section of the optic nerve near the retina. Dots indicate regions containing axons filled with HRP reaction product. The orientation of the nerve was lost when it was cut off the retina. Scale line equals $100 \mu \mathrm{m}$ and applies to $B$ also. $B$, Cross-section of the optic tract near the tectum. The dorsal, superficial surface is at the top. Large arrows indicate layers of axons filled with HRP reaction product. The small arrow indicates a layer of axons in which only some of the axons are filled with HRP reaction product. The arrowhead indicates a blood vessel crossing the tract which should not be confused with the layers of filled axons. $C$, Tracing of a sector of the retina which was attached to the nerve shown in $A$. The optic disc is at the top, and the peripheral margin is at the bottom. Dots indicate regions containing ganglion cells filled with HRP reaction product. Arrows connect the same regions shown at higher magnification in $D$. Scale line equals $200 \mu \mathrm{m}$. $D$, Photograph of the central region of the retina shown in C. Arrows indicate bands of ganglion cells filled with HRP reaction product. Arrowheads indicate filled ganglion cells in a much less densely filled band. Scale line equals $100 \mu \mathrm{m}$. The dark background is a layer of pigment which remained attached to the retina when it was separated from the pigmented epithelium.

currently working with another species of perciform fish, the rainbow cichlid (Herotilapia multispinosa, suborder Percoidei, family Cichlidae), and have performed similar injections into the optic nerve of over 60 of these fish aged 2 months to 1 year. Whenever the retina is relatively free of pigment so that ganglion cells can be seen, the pattern of filled ganglion cells matches the pattern predicted by Scholes's model.

Within the optic nerve, bands of axons filled with $\mathrm{HRP}$ reaction product remain together most of the distance between the retina and tectum. As an illustration, in the optic nerve shown in Figure 2, cross-sections from the first $2.4 \mathrm{~mm}$ of the $3.4 \mathrm{~mm}$ between the retina and tectum were virtually indistinguishable from Figure $2 A$. (Very few, if any, axons cross over to the other optic tract at the chiasm in these fish, so the optic tract is just a continuation of the optic nerve.) However, as noted in other fish with ribbon-shaped optic nerves, before the optic tract splits into two brachia, the tract loses its ribbon shape and becomes rounded without any grossly obvious internal subdivisions, and the axons within the tract undergo a gross rearrangement (Anders and Hibbard, 1974; Bunt and Horder, 1978, 1983; Scholes, 1979). Figure 2, $B$ through $F$, illustrates this rearrangement. The paths of individual axons of the same age with respect to each other are very difficult to determine in 

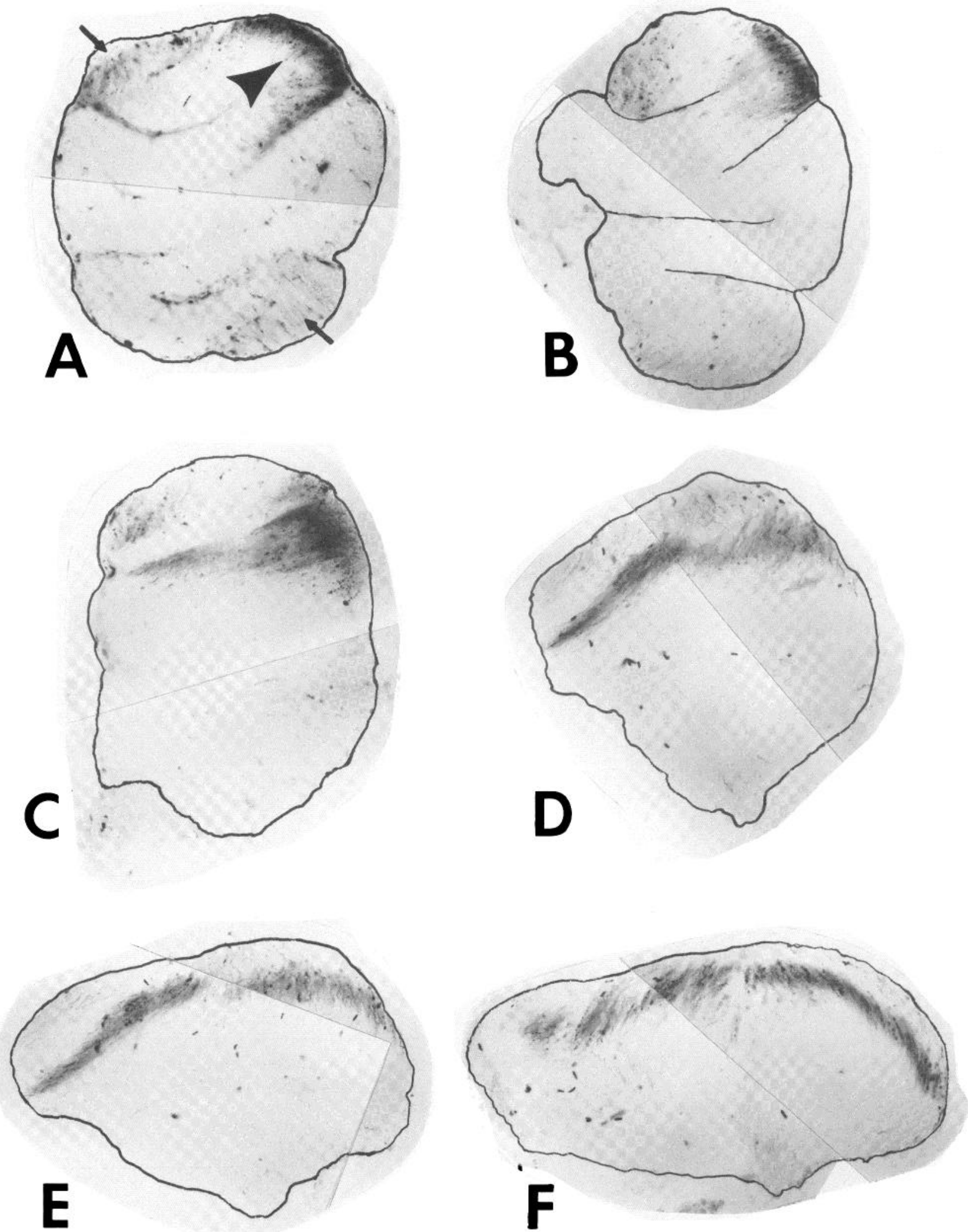

Figure 2. Photographs of a series of cross-sections from the optic nerve and tract of a pink kissing gourami in which one band of axons (large arrowhead) was filled with HRP reaction product. A few axons at each side of the ribbon-shaped nerve (small arrows) also filled with HRP reaction product. This series shows the transformation of the band of filled axons in the nerve into a layer near the tectum. All sections are shown at the same magnification; scale line equals $200 \mu \mathrm{m}$. The sections near the tectum are shown with the dorsal, superficial surface at the top; the orientation of sections near the retina is not known as the entire nerve is normally twisted between the retina and tectum; this twist is lost when the retina is cut off the nerve. $A$, Section of the optic nerve $1.4 \mathrm{~mm}$ from the retina. This section appears similar to most of the sections between the retina and the section shown in $B . B$, Section of the optic nerve $1.0 \mathrm{~mm}$ distal to $A$. The ribbon-shaped appearance of the nerve is beginning to be distorted, and some axons are running in the plane of the section rather than transverse to it as in $A$. $C$, Section $500 \mu \mathrm{m}$ distal to $B$. The nerve no longer has a ribbon-shaped appearance, and many axons extend across the width of the nerve. $D$, Section $300 \mu \mathrm{m}$ distal to $C$. Axons are beginning to turn again so that they are once again running in the direction of the tectum. $E$, Section $50 \mu \mathrm{m}$ distal to $D$. F , Section $100 \mu \mathrm{m}$ distal to $E$. The section $100 \mu \mathrm{m}$ distal to this section contained the first part of rostral tectum. Unlike in the goldfish, the optic tract does not physically separate into two brachia in this species until it actually contacts rostral tectum. 


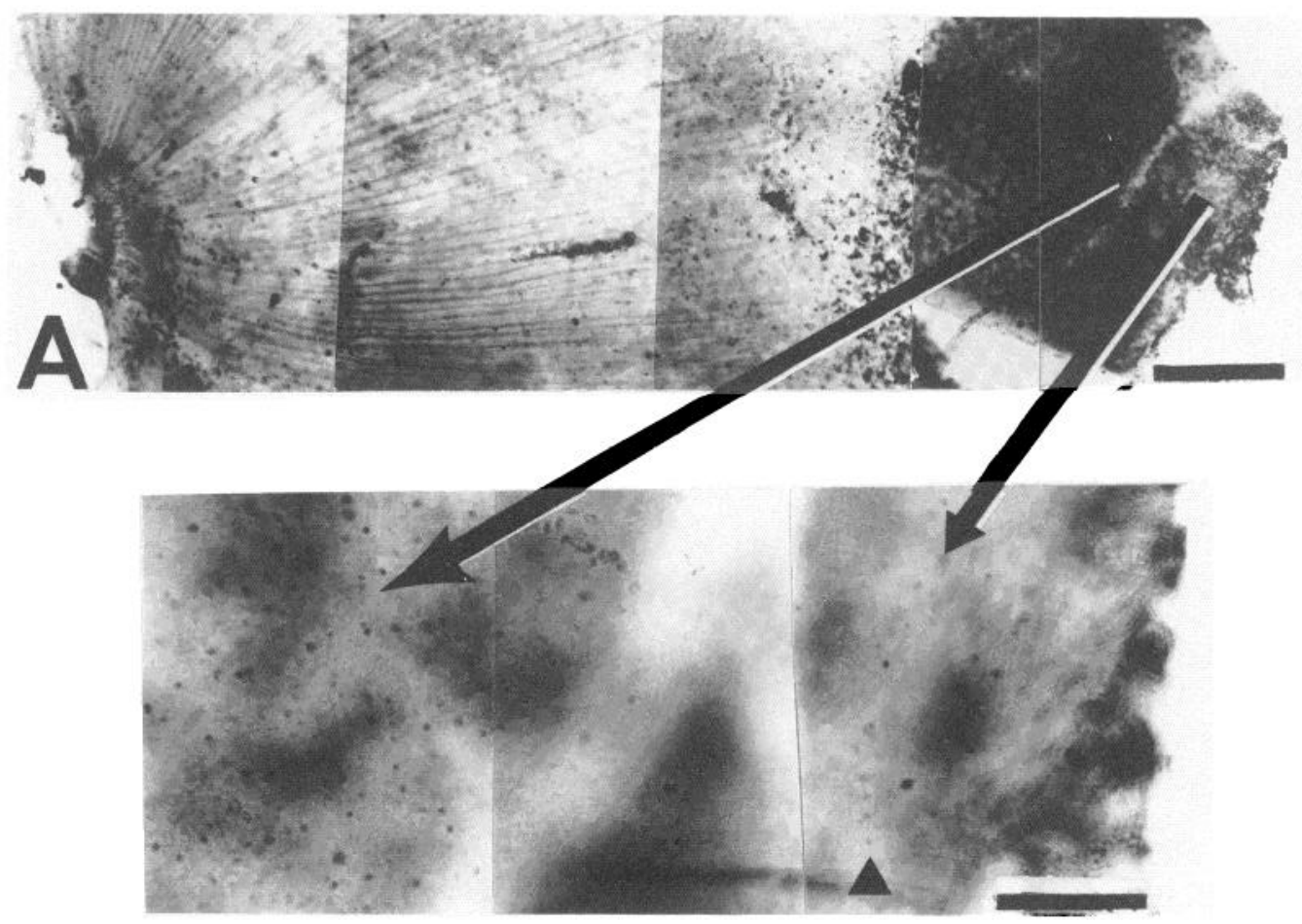

Figure 3. Photomosaics of a sector of the retina which was attached to the nerve shown in Figure 2. A, The optic disc is shown at the left and peripheral margin at the right. Axons filled with HRP reaction product are visible crossing the retina until they are masked by the presence of dark pigmented epithelium still attached to the retina near the margin. Scale line equals $350 \mu \mathrm{m}$. $B$, A higher magnification view of the peripheral margin of this retina. Arrows indicate the positions of two bands of ganglion cells filled with HRP reaction product. One is wide and contains many cells; the other, which is nearer to the peripheral margin, is only one cell wide. Scale line equals $100 \mu \mathrm{m}$.

these preparations since all of the axons of the same age are filled; thus, the movement of axons from different retinal positions relative to each other mentioned by Scholes (1979) cannot be detected. However, in the goldfish, I have filled all of the axons from one brachium with HRP and traced the filled axons back through the bifurcation of the optic tract. In these fish in which there is no change in the shape of the tract, there is a clear rearrangement of axons of the same age with respect to each other. Axons from ventral retinal ganglion cells which were on the lateral side of the optic tract make a right angle turn and cross the tract to join other axons from ventral retinal ganglion cells which were on the medial side of the optic tract. One of my preparations demonstrating this is illustrated in an article by Constantine-Paton (1982). Presumably, this type of sorting is also part of the rearrangement which is illustrated in Figure 2 since axons from ventral retina are separated on the two sides of the band in the ribbon-shaped portion of the nerve in perciform fish (Scholes, 1979) but are all together in the dorsomedial portion of the optic tract as it enters the tectum. Unfortunately, the brachial filling experiment is technically very difficult in these fish; I am in the process of attempting other experiments to separate the component of this rearrangement which represents real sorting of axons from a simple change in the shape of the optic tract. The final result of the rearrangement is that axons which are in a band in the ribbon form a layer in the optic tract (Figs. $1, A$ and $B$, $2, A$ to $F$, and $5, B$ and $C$ ). In the experiment shown in
Figure 1, the injection of HRP resulted in reaction product only in central retinal ganglion cells (Fig. 1, $C$ and $D$ ); a section from the optic tract (Fig. $1 B$ ) shows that axons from these cells form layers deep in the optic tract. (The relatively superficial dark band in Figure $1 B$ which is indicated by the arrowhead is a line of blood vessels; the axons filled with HRP reaction product are confined to the deep layers in the tract indicated by the arrows.) In the experiment shown in Figures 2 and 3, the reaction product was mostly in a large band of ganglion cells near the peripheral margin of the retina (Fig. 3 ); Figure $2 F$ shows that these axons form a layer near the superficial surface of the optic tract. (The very narrow band of filled ganglion cells closer to the retinal margin and the cluster of central cells filled with reaction product are represented in the optic tract by a few axons almost at the superficial surface and a few deep in the tract, respectively. Figure 5 shows parts of the visual system from a fish in which HRP was applied to only the edge of the optic nerve (Fig. $5 B$ ). In the tract near the tectum (Fig. $5 C$ ), these filled axons form the most superficial layer. The retina which was attached to this nerve has a heavy layer of adhering pigment so that the pattern of filled ganglion cells could not be photographed; however, only ganglion cells at the peripheral margin are filled with reaction product. Thus, in the optic tract near the tectum and at the rostral lip of the tectum the youngest axons (from peripheral retinal ganglion cells) are superficial and the oldest axons (from central retinal ganglion cells) are deep in the tract and closest to the surface of the 
tectum. At the rostral edge of the tectum, each of these age-related layers is nearly as wide as the whole rostral edge of the tectum.

The majority of the axons do not remain spread across the width of the tectum as they cross its surface. Instead of forming straight lines across the tectal surface, a large portion of them change course and reform bands which arc around the tectum, as seen on Figures 4,5 and $6 A$. In each case there are two bands of axons filled with HRP reaction product on the tectal surface for each band of axons filled in the nerve and retina. One band is present in the dorsal half of the tectum and the other in the ventral half. (Different authors use different designations for the various parts of the tectum. When the tectum is in the fish, the two margins of it are medial and the part of the tectum farthest from the margins is lateral; the dorsal margin is closer to the midline than the ventral margin is. I will refer to the part of the tectum farthest from the margins as central tectum, to the part of the tectum from the dorsal margin to central tectum as the dorsal half, and to the part of the tectum from central tectum to the ventral margin as the ventral half of the tectum.)

Figure 4 shows the tectum which was attached to the nerve shown in Figure 2. Filled axons form a layer which covers the rostral edge of the tectum. A short distance from the rostral edge this layer is converted to two bands indicated by large solid arrowheads on the dorsal side of the tectum (Fig. 4). The larger band is formed by axons from the large band in the optic nerve, and the smaller band is formed by axons from the band indicated by the upper small arrow in Figure $2 A$. Only the large band is in focus at the ventral margin of the tectum, although the smaller band is also present in the tissue. (Small arrows on Figure 4 indicate a few of the axons which came from the group of axons indicated by the lower small arrow in Figure 2A.)

Figure 5 shows a tectum in which only the axons from most peripheral retinal ganglion cells are filled with HRP reaction product. The filled axons are clearly near the margin of the tectum. The absence of axons filled with HRP reaction product on central tectum is quite striking. Even those axons which terminate in the most caudal part of the tectum are always near the margin of the tectum rather than on central tectum.

A third tectum is shown in Figure 6. In this case axons from two relatively central anuli of retinal ganglion cells are filled with HRP reaction product. (The retinal ganglion cells which filled with HRP reaction product are shown in Figure 8.) On the dorsal half of the tectum two bands of axons (solid arrows) form arcs over the tectal surface. These bands are not at the margin of the tectum but, rather, are internal to it. The bands of axons on the ventral side are out of the plane of focus.

Many axons which terminate in the rostral portion of the tectum do not join the bands coursing around the tectum. Instead, they form relatively straight lines from the rostral lip of the tectum to their terminations (Figs. $6 \mathrm{~A}$, arrowheads, and $10 \mathrm{~A}$ ). Although the origination of these axons is obscured both by the tendency of this part of the tectum to curl under in the whole mount and by the layers of axons entering the tectum at this point, the majority of these axons appear to have left the other axons in their age-related layer as it approached the rostral lip of the tectum and to have gone directly into rostral tectum toward their target of termination. I have never seen an axon which terminates rostrally emerge from a band caudally and have a portion which crosses back across the tectum toward its termination zone.

On each tectum axons emerge from the bands and form anuli of terminals. Figure 7 shows the tectum which was attached to the nerve shown in Figure 1. This tectum was photographed before it was flattened, dehydrated, and cleared so that the shape of the anuli of terminals could be seen easily. Since the tectum was quite curved at this time, only one band of axons crossing the tectum (solid arrowhead) is in focus. However, three anuli of terminals (open arrowheads), centered on the tectum, are in focus; these anuli correspond to the three bands of filled axons in the nerve and tract and to the three anuli of filled ganglion cells in the retina-the two wide, dark anuli correspond to the larger bands of axons in the nerve and tract and to the wide bands of filled ganglion cells; the middle, narrower ring of terminals corresponds to the smaller, partial band of filled axons in the nerve and tract and to the narrow band of filled ganglion cells indicated by small arrowheads in the retina (Fig. 1).

In Figure 4 the rostral portion of an anulus of terminals is clearly visible near the peripheral margin of the tectum (open arrowheads); caudally, the terminals are underneath the band of axons and are obscured. In Figure $5 A$, the anulus of terminals is at the peripheral margin of the tectum, both directly under the axons at the margin and slightly central to the axons (open arrowheads). Figure $6 A$ shows a second tectum in which the anuli of terminals filled with HRP reaction product (open arrows) are relatively central. Although the anular shape of each terminal zone was distorted by the cuts made to flatten the tectum, the pattern is still very evident. The retina which contained the cell bodies of these axons also has two anuli of filled ganglion cells (Fig. 8). In all cases for each anulus of terminals filled on the tectum, there is a corresponding anulus of ganglion cell bodies filled on the retina. Note that in Figure 6, as in Figure 7, the anuli of terminals from central retinal ganglion cells are roughly centered on the tectum, and the anuli of ganglion cells in Figure 8 are roughly centered around the optic disc. Each anulus of terminals is formed from two half-anuli; terminals from axons which are in the band on the dorsal half of the tectum form one half-anulus, and terminals from axons in the band on the ventral half of the tectum form the other. The zone where the two half-anuli meet is very obvious in caudal tectum. Here the same field of view contains terminals from axons which cross around the tectum on the dorsal edge and from axons which go around it on the ventral edge (Fig. 9).

Axons emerge from the bands and approach their zones of termination in different ways, depending on the position of the arbor on the tectum. Axons terminating in rostral tectum generally have a relatively straight course across rostral tectum and simply bifurcate near the terminal zone and then branch further (Fig. 10A). 


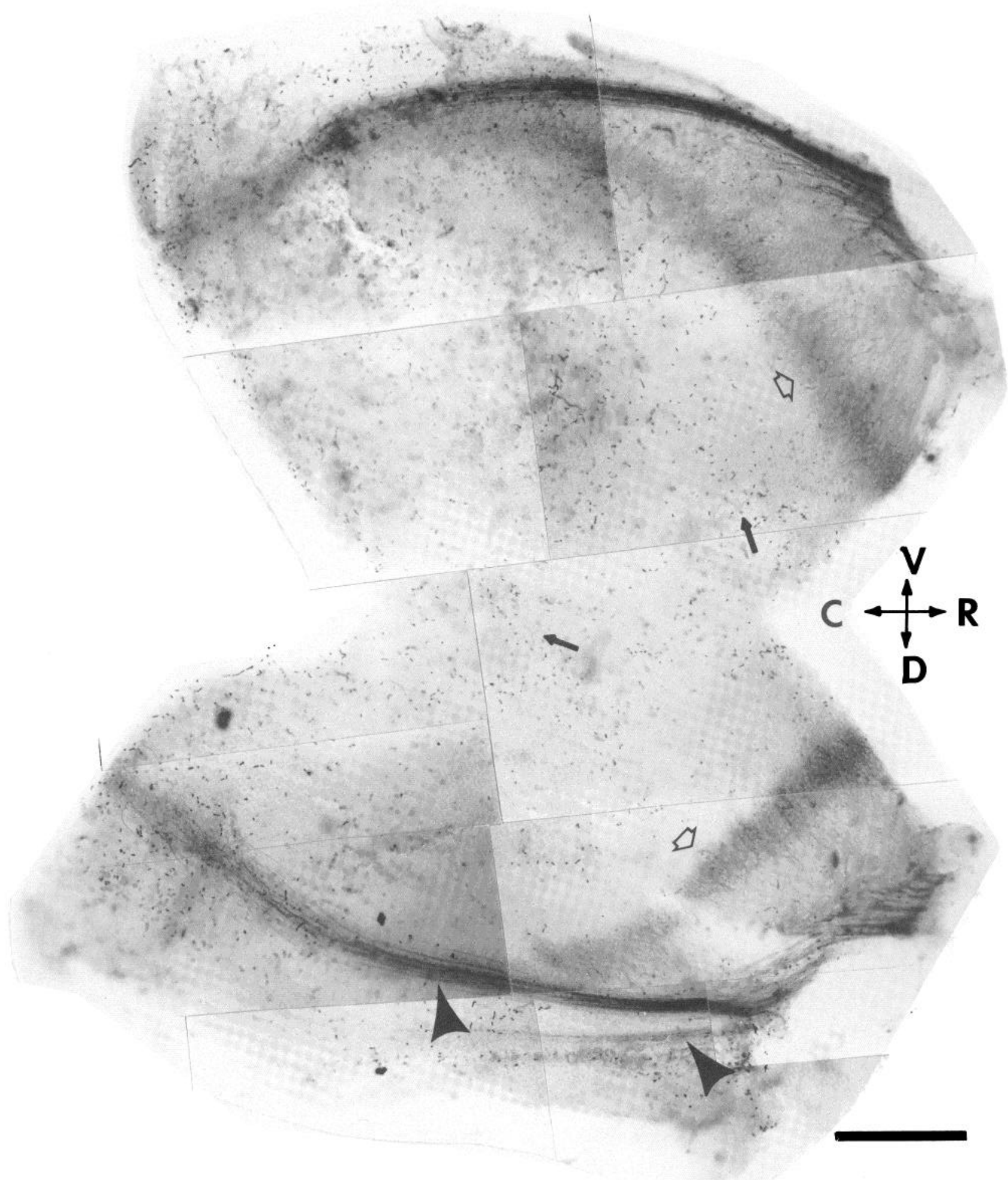

Figure 4. Photomosaic of the tectum which was attached to the nerve and retina shown in Figures 2 and 3 . Solid arrowheads indicate bands of axons crossing the tectum; open arrowheads indicate a ring of axon terminals derived from the axons in the larger band. Small arrows indicate a few isolated axons terminating on central tectum. $R$, rostral; $C$, caudal; $D$, dorsal; $V$, ventral. Scale line equals $400 \mu \mathrm{m}$.

Axons which leave the bands of axons in dorsal or ventral tectum generally angle off from the band, running centrally and sometimes caudally before bifurcating and then forming multiple branches in the terminal zone (Fig. 10B). Axons which terminate in caudal tectum leave their bands in characteristic patterns, depending on whether the band of axons is close to the peripheral edge of the tectum or more central. Axons in the most peripheral bands characteristically make a sharp turn of nearly $90^{\circ}$ and turn toward the central part of the tectum before 

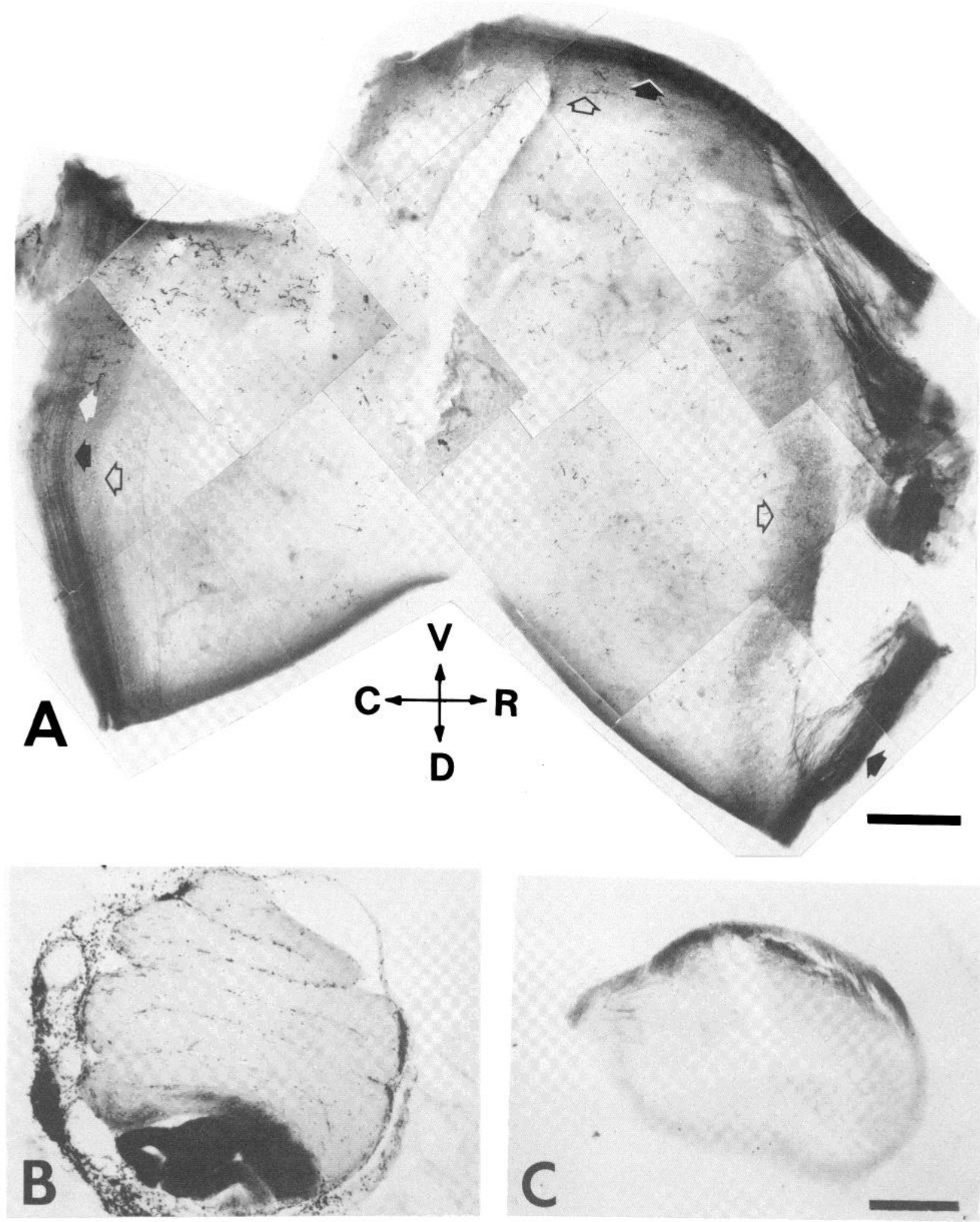

Figure 5. Photographs of parts of the visual system of a pink kissing gourami in which one edge of the optic nerve was cut near the retina and coated with HRP. A, Photomosaic of the entire flat-mounted tectum which was attached to the nerve treated with HRP. The tectum was flattened after making two oblique cuts into it. Solid arrows indicate the band of axons filled with HRP reaction product at the dorsal, ventral, and caudal margins of the tectum. The open arrows indicate the band of terminal arbors from these axons forming a ring just central to them. On rostral tectum the band of terminal arbors is at the rostral margin of the tectum. The white arrow indicates region shown in Figure $9 . R$, rostral; $D$, dorsal; $V$, ventral; $C$, caudal. $S$ cale line equals $0.5 \mathrm{~mm}$. $B$, Photograph of a $40 \mu \mathrm{m}$ thick cross-section taken from the optic nerve slightly less than half way from the retina to the tectum. (When the retina was cut off of this nerve, the orientation of the nerve was accidentally lost so the orientation of this section with respect to the axes of the fish is not known. In another perciform fish, Herotilapia multispinosa, axons from the most peripheral ganglion cells are on the ventral edge of the nerve so this nerve is shown in that orientation.) The compressed ribbon shape of the nerve is very evident at this point. Axons filled with HRP reaction product are seen as a dark region filling one edge of the ribbon. Scale is the same as that for part $C$. $C$, Photograph of a $40 \mu \mathrm{m}$ thick section of the optic tract near the tectum. Dorsal is at the top. The circumference of the optic tract is outlined by the dotted line. This portion of the tract does not have the ribbon shape of the nerve and its internal compartmentation. The axons filled with HRP reaction product form a dark band across the superficial surface of the section. Scale line equals $0.3 \mathrm{~mm}$. 


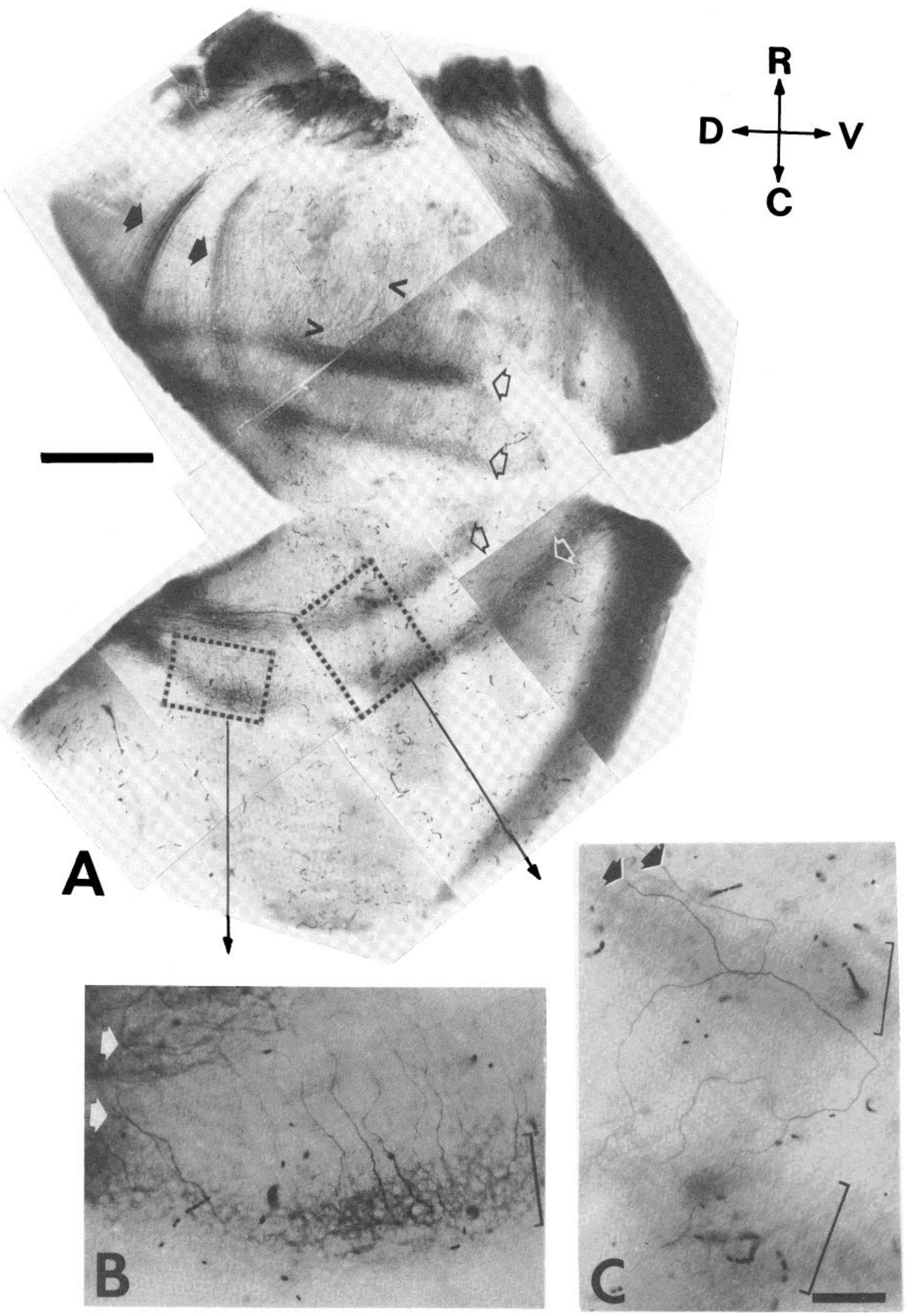

Figure 6 


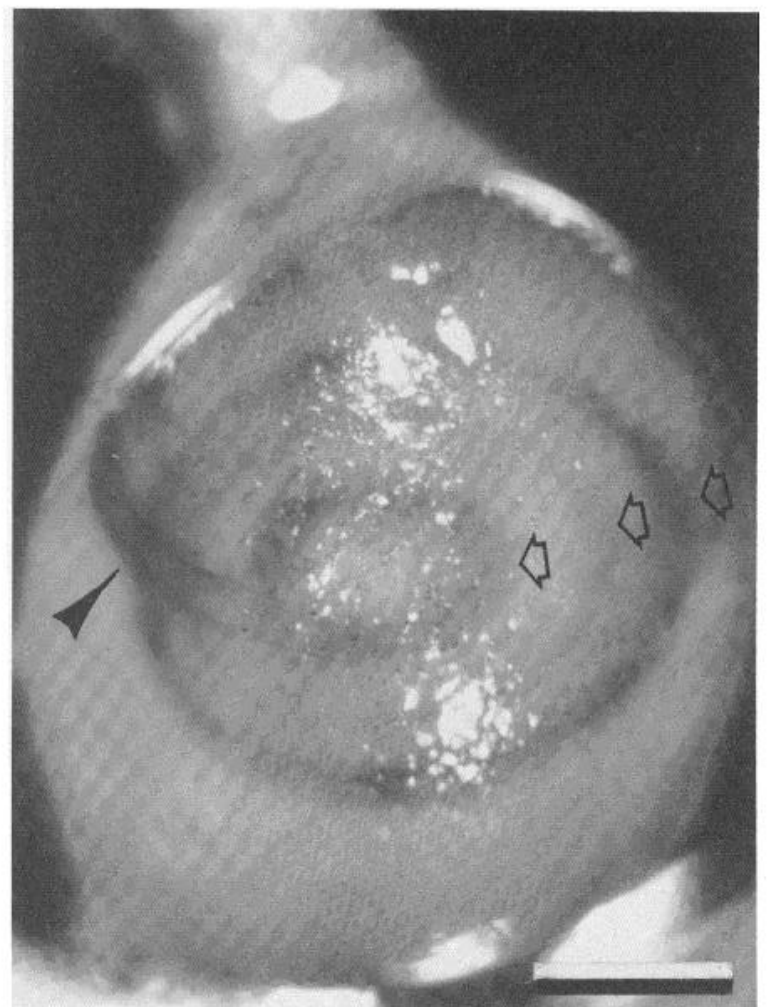

Figure 7. Photograph of the tectum which was attached to the optic nerve shown in Figure 1. This photograph was made before the optic nerve (top) was severed from the tectum and the tectum was dehydrated and cleared. The solid arrowhead indicates a band of axons crossing the tectum on its dorsomedial side, and the open arrowheads indicate three anuli of terminals filled with HRP reaction product. Scale line equals $500 \mu \mathrm{m}$.

beginning to bifurcate (Fig. 10C). This pattern can also be seen very clearly on the tectum shown in Figure 5. Only the most peripheral axons are filled with HRP reaction product, and the anulus of filled terminals (open arrows) is clearly central to and/or underneath the band of filled axons coursing around the edge of the tectum (solid arrows). Slightly less peripheral axons terminate directly underneath the band of axons with no component terminating central to the course of the axons around the tectum (Fig. 4).

Axons which terminate in more central caudal tectum have a different path away from the band in which they crossed the tectum. When they leave this band, they often turn peripherally and form terminal anuli which are peripheral to the bands in which they crossed the

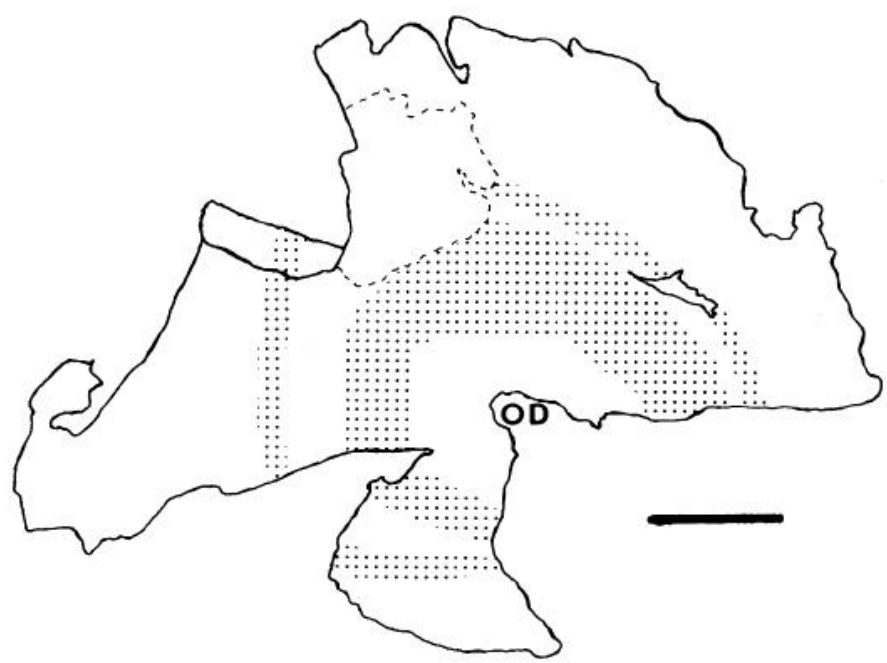

Figure 8. Tracing of the retina which was attached to the same optic nerve as the tectum shown in Figure 6. Dots indicate the positions of ganglion cells filled with HRP reaction product. The dashes encircle a region coated with a thick layer of pigment so that the positions of filled ganglion cells in that region could not be determined. $O D$, optic disc. Scale line equals $2 \mathrm{~mm}$.

tectum. Close examination of Figure $6, B$ and $C$, which are higher magnification views of the regions indicated by boxes on Figure $6 A$, reveals that the axons which terminate in the most peripheral anulus actually crossed the tectum in the band which overlies the inner anulus of terminals. (The bands of axons cross the tectum in a layer which is superficial to the layer in which their terminals are located; this stratification makes it possible for a band of axons to overlie an unrelated anulus of terminals, as illustrated in Figure 6.)

When many axons are filled with HRP reaction product, as in Figures 4, 5, and 6, the bands of axons near the surface of the tectum and the terminal zones can be clearly defined. However, tracing individual axons for long distances across these tecta is difficult because the individual filled axons are hard to separate from the mass of filled processes. In some preparations, only a few axons were filled with HRP reaction product. Then it was possible to trace axons along much of their length in the tectum. A photomosaic of axons on one such tectum is shown in Figure 11. These axons all terminate in the appropriate annular zone on the tectum, but the paths which the axons take to get to this zone are quite divergent. Therefore, near the point at which the axons

Figure 6. A, Photomosaic of the flat-mounted tectum from a pink kissing gourami in which the connective tissue sheath around the optic nerve was slit open, allowing the ribbon of the nerve to flatten out, before an insect pin coated with HRP was inserted twice into the nerve. The solid arrows (top left) indicate two bands of axons filled with HRP reaction product on the dorsal side of the tectum; similar bands on the ventral side are out of focus. Open arrows indicate each of the two halves of the two anuli of terminal arbors filled with HRP reaction product. $R$, rostral; $D$, dorsal; $V$, ventral; $C$, caudal. Scale line equals 0.5 $\mathrm{mm}$. Boxes indicate the regions of the tectum shown at higher magnification in $B$ and $C$. $B$ and $C$, Individual axons (solid arrows) leaving the band of axons and turning caudally before branching in the terminal zone (brackets). In $C$ note that the axons indicated with solid arrows are directly above the more central terminal zone (shorter bracket). Axons which terminate in that zone are visible but not in focus approaching the terminal zone from the yet more central band. Scale is the same for $B$ and $C$; scale line equals $100 \mu \mathrm{m}$. 


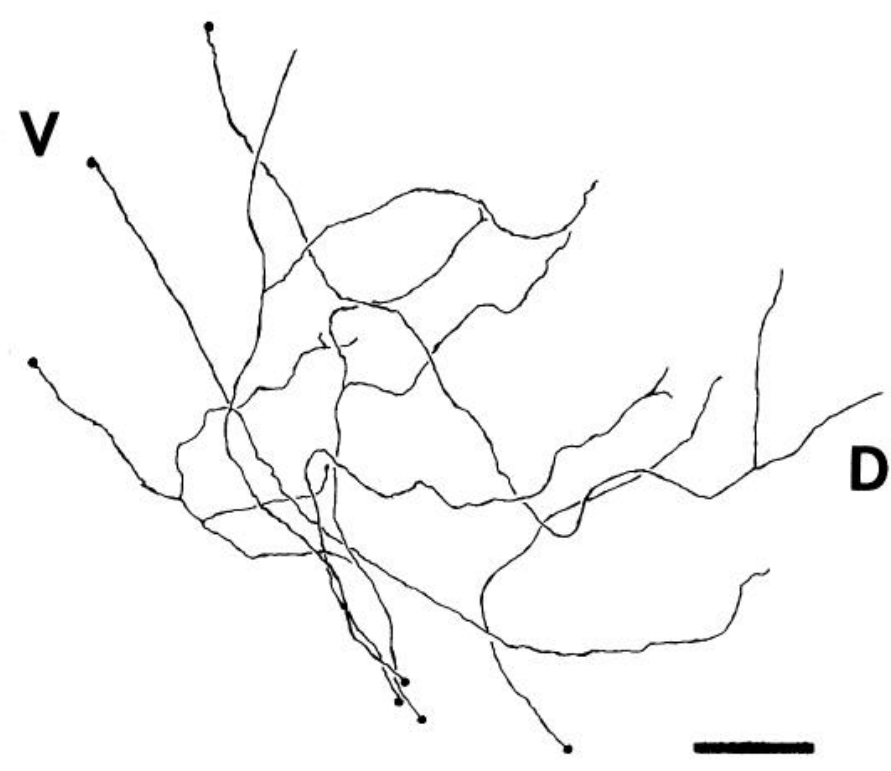

Figure 9. Tracing of parts of seven axons. The axons are from the caudal region on Figure $5 A$ indicated by the white arrow and terminate central to the band of axons. Axons were traced to show their positions between the band of axons and the zone in which they terminated. No attempt was made to draw the fine branches in the terminal zone. The large dot at the end of each axon indicates the direction from which the axon approached the terminal zone. These axons are representative axons; many other axons with similar paths are present in this region. The axons shown have an overlapping distribution about $250 \mu \mathrm{m}$ wide. $D$, dorsal; $V$, ventral. Scale line equals $50 \mu \mathrm{m}$.

terminate, their paths seem to be at least somewhat independent of the paths of their neighbors.

\section{Discussion}

In this study I have examined the visible positions of axons and their terminals in the optic pathway of late juvenile to adult perciform fish. The results demonstrate that axons from ganglion cells in the specific anuli of the retina are found in specific places within the group of axons at each point in the optic pathway. In interpreting these results, I have assumed that the position of an axon in these relatively old fish reflects the path which that axon initially took as it grew out from the retina to the tectum. My assumption implies that once a growth cone has grown by a given point, the axon it has laid down behind it is relatively fixed in place with respect to surrounding axons. Therefore, one can learn about the path which an axon's growth cone took by looking at the position of the axon some time later. This assumption need not imply that axons cannot change; clearly, as a fish grows larger, the distance between the retina and tectum increases and the length of axons must increase. My presumption is that neighboring axons change in the same ways so that the axons which grew to the tectum side by side will still be near each other later. In some species, outside influences, such as subsequent fasciculation by glia (in goldfish-Easter et al., 1981; Bunt, 1982), selective myelination and/or increases in diameter of axons (possibly in Xenopus-Cima, 1979), or differ-
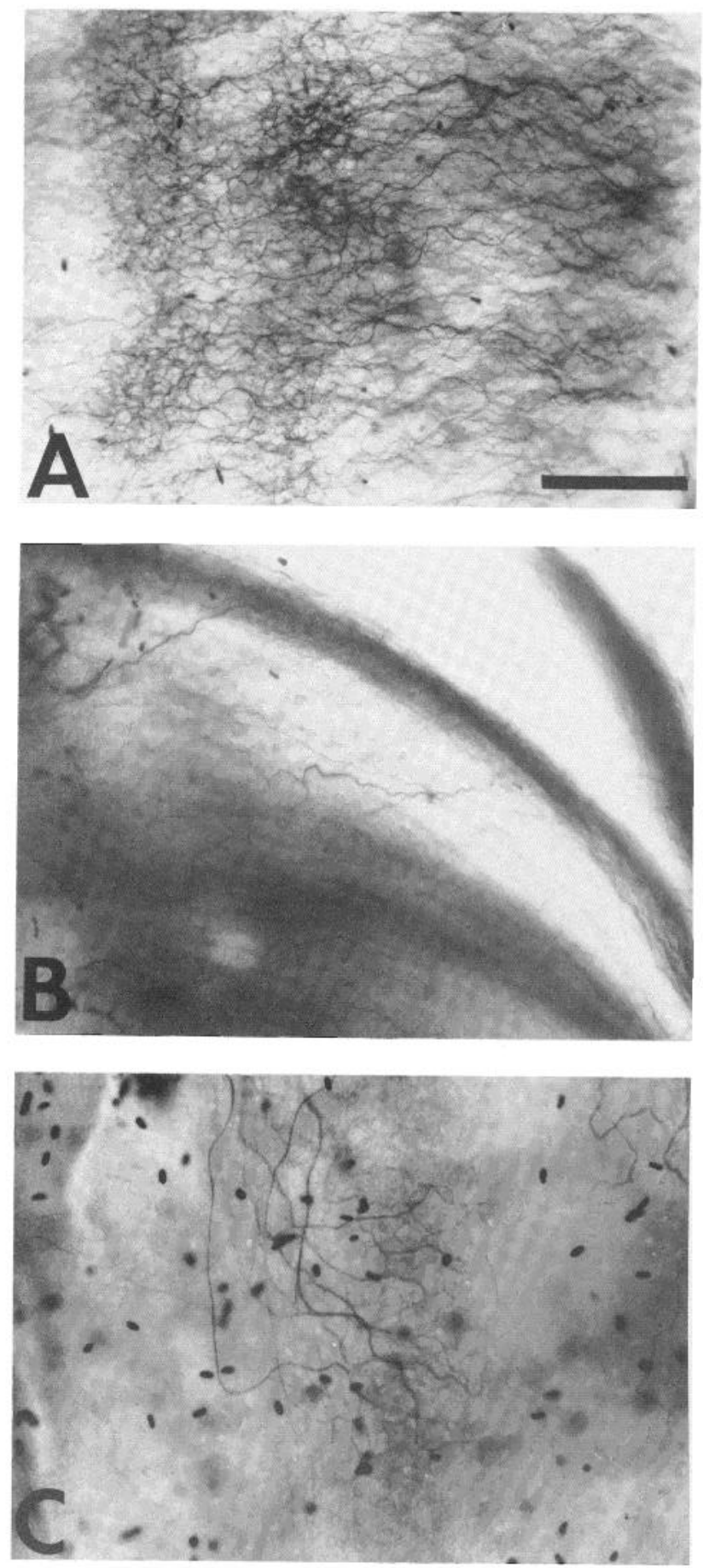

Figure 10. Photographs of individual axons filled with HRP reaction product on a tectum. In all cases the orientation is the same; rostral is to the right and ventral is up. The scale line in $A$ applies to all three photographs and equals $50 \mu \mathrm{m}$. $A$, Axons which cross rostral tectum (right) and branch in one of two bands of terminal arbors (left). $B$, Axons which leave a band of axons in ventral tectum and branch in a band of terminal arbors central to their original band of axons. $C$, Axons on the most caudal part of the tectum which leave their band by turning sharply toward central tectum and form a band of terminal arbors central to the band of axons.

ential death of retinal ganglion cells after outgrowth of axons (in rat-Lam et al., 1982; in cat- $\mathrm{Ng}$ and Stone, 


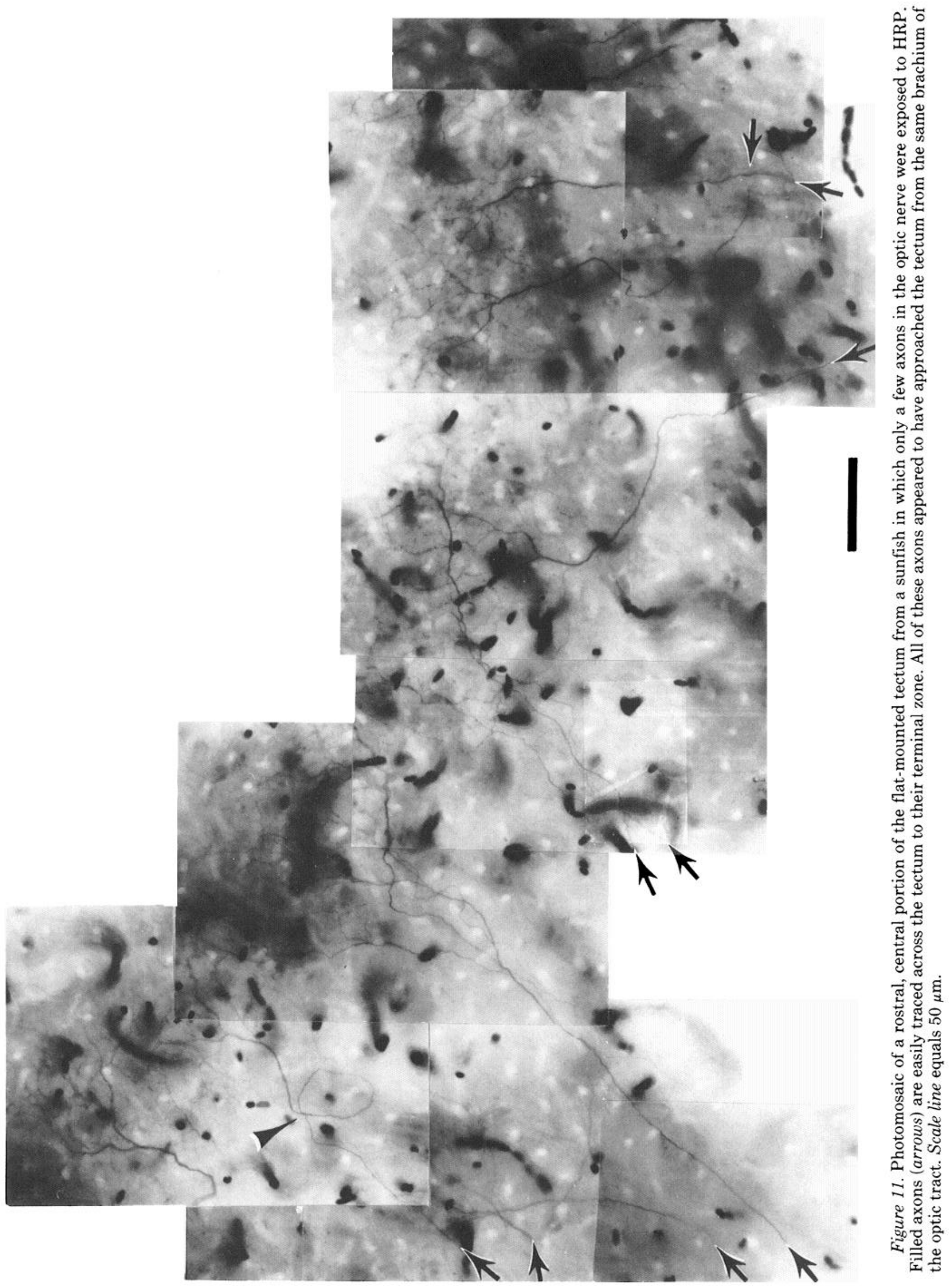


1982; in rhesus monkey-Rakic and Riley, 1983), may perturb this organization. However, in the perciform fish with which I have worked the specificity of the pattern of organization and its high reproducibility between fish strongly suggest that the initial pattern of outgrowth of axons has been at least grossly preserved. Furthermore, these fish presumably still have new axons growing down the optic nerve so cues for appropriate growth and connections must still be present.

If one accepts the idea that axons which are near each other in the large fish grew across that part of the optic pathway together, one can use the organization of the optic path to determine whether axons behave as if they are being strictly mechanically guided throughout the pathway or whether they appear to need additional information to find their appropriate targets. In these perciform fish the nerve takes on the ribbon-shaped configuration a short distance from the optic nerve head. At this point the oldest axons appear to act as a guide, and each successive wave of axons uses the last wave of axons as a growth surface. This idea is included in the model of Scholes (1979) for perciform fish and has also been proposed for goldfish (Horder and Martin, 1978; Bunt et al., 1979; Easter et al., 1981; Bunt, 1982) and for the zebrafish, a species in the same family as goldfish (Bodick and Levinthal, 1980). As shown in Figure 2, this organization is at least grossly retained in the optic nerve of perciform fish throughout most of the length of the nerve and only disappears as the axons begin reorganizing before separating into the two brachia of the optic tract. In goldfish this age-related type of organization is present at the nerve head (Easter et al., 1981; Bunt, 1982) but does not remain as clear throughout the length of the optic nerve. However, goldfish have a round optic nerve which is fasciculated by an invasion of glia. Possibly the nerve is initially as well organized along its length in goldfish as in the perciform fish, but with the division of the nerve by glia this organization is masked. Thus, the general rule may exist in fish that as axons reach the optic nerve, they use the most recently added axons as a substrate to grow over and, if undisturbed, grow down that substrate until receiving some information to change paths.

The nature of the information in the optic tract which causes axons to change course and rearrange before they reach the two brachia is presently unknown. In goldfish, the rearrangement is very dramatic; individual axons turn abruptly and cross the width of the nerve as axons from ventral retinal ganglion cells separate themselves from axons from dorsal retinal ganglion cells (see Fig. 1 of Constantine-Paton, 1982). In the perciform fish studied here, the rearrangement is more confusing since the shape of the nerve is changing in the same region where the segregation of axons noted by Scholes (1979) must be occurring, but the effect is the same; axons sort and rearrange themselves so that all of the axons of the same age form a layer in the tract, and those axons from ventral retinal ganglion cells which will enter the tectum via the dorsomedial brachium are separate from those axons from dorsal retinal ganglion cells which will enter the tectum via the ventrolateral brachium.

Horder and Martin (1978) hypothesized that axons were layered by age as they approached the tectum in goldfish, and Bunt (1982) has presented some evidence for this hypothesis. Figures 1, 2, and 5 demonstrate that the hypothesis is clearly true in these perciform fish. Thus, after the rearrangement of axons and before the bifurcation of the optic tract has occurred, axons are once again in position to use older axons as a substrate to grow over until they actually reach the tectal surface.

As the growing wave of axons reaches the rostral lip of the tectum, it is on top of all of the older axons and basically spread out across the width of the rostral tectum. The ingrowing axons from temporal retinal cells which will terminate in the most rostral portion of the tectum (Leghissa, 1955) leave the other axons sometime before the layer approaches the rostral lip of the tectum and grow relatively straight toward their terminal zone. The cue which causes these axons to separate off is not known. Some authors have speculated that the only cue present is physical proximity to an unoccupied terminal zone (Horder and Martin, 1978; Bunt et al., 1979). Growth of the tectum in the perciform fish has not been specifically studied; however, in goldfish (Meyer, 1978; Raymond and Easter, 1983) and Xenopus (Straznicky and Gaze, 1972), the tectum grows by adding new neurons in a horseshoe-shaped region excluding rostral tectum, so that rostral tectum in a juvenile or adult goldfish or amphibian does not receive new neurons. Presumably, the tectum of perciform fish grows in this way also. Therefore, ingrowing axons find terminals already at the margin of the rostral tectum and must force these older terminals centrally to provide terminal space for themselves. The presence of relatively concentric rings of terminals on the tecta shown here, especially on Figures 6 and 7, indicates that this shift does occur. Otherwise the anuli of terminals would lie on top of each other rostrally or, minimally, be distorted there. Thus, while the axons from temporal retinal cells may indeed be the closest ingrowing axons to the rostral terminal zone, the zone in which they will terminate is not "empty" and waiting for them.

The remaining ingrowing axons coalesce from the broad layer at the rostral lip of the tectum to a band at each margin and grow in an arc around the edge of the tectum rather than straight toward their destination. As the ingrowing axons grow around the edges of the tectum, individual axons leave the group and either grow slightly centrally before entering the synaptic zone or turn down immediately into the synaptic zone and begin to bifurcate and form terminals. The few axons which grow to the most caudal edge of the tectum terminate either in the synaptic zone at the very margin of the tectum or make a sharp turn and grow centrally before terminating. Thus, axons normally grow across the tectum in such a way that they are always close to the most peripheral synaptic zone and are not crossing the parts of the tectal surface which are occupied by much older axons.

Once axons reach the synaptic zone and make connections, they do not cease growing. Assuming that the tectum grows as described earlier and does not add new neurons rostrally, rostral terminals must shift centrally to make room for new terminals from temporal retina. Other terminals must then shift to recenter the retinal 
map on the tectum as the map shifts caudally and to keep the parts of the map generally aligned internally. The idea that connections must shift was initially proposed by Chung et al. (1974), who were working with the Xenopus retinotectal system, and it was extended to the goldfish by Meyer (1978). Easter and Stuermer (1982) have proposed a model for this shifting in the goldfish which defines two stages in the growth of an axon-the initial path and the secondary trajectory. According to them, the bands of axons mark the initial paths of axons to their first termination sites. Later, as the terminals are forced to move, they grow through the synaptic layer away from the arcing fibers of the bands on the surface of the tectum; the final position of the terminal (the position at the time when the fish is killed) will be caudal to the end of the arcing path of the band and will be connected to that band by a relatively straight piece of axon running caudally across central tectum. Preliminary evidence concerning their model can be obtained from the tecta depicted here since the paths of axons from different retinal anuli can be compared on them easily. A comparison of the paths of axons reaching the caudal part of the tectum in Figures 4, 5, and 6 shows that the predictions of Easter and Stuermer are met. The axons which have grown into the tectum recently (Fig. 5) terminate central to the arc of their axons; axons which are from slightly older retinal cells terminate directly under their arc of axons (Fig. 4); and the axons which grew into the tectum long before (Fig. 6) have left the position central to the arc and have grown caudally. At the time the fish was killed, these axons terminated peripheral to the region of tectum confined within the arc of the initial paths of their axons (Fig. 6,B and $C$ ). Since the arc of the initial paths of newly ingrown axons surrounds the entire tectum which exists at that time (Fig. 5), at the time the fish shown in Figure 6 was killed, the axons shown in Figure 6, $B$ and $C$, terminated in a portion of the tectum which did not yet exist when they first grew out over the tectum. Thus, the shifting of axon terminals necessary to maintain a centered retinotopic map on the tectum can be clearly visualized in these fish and does follow the predictions of Easter and Stuermer. These observations and those mentioned earlier comparing the organization of axons in the optic nerve in goldfish and perciform fish suggest that axons in the visual system of these fish respond similarly to their environment and to each other even though the two types of fish are only distantly related.

A final question can be addressed using the preparations presented here: Must axons terminate next to the axons which were their neighbors as they crossed the tectum? Some of the strict mechanical guidance models governing the finding of termination sites require a "yes" answer to this question. Figures 9 and 11 show the ends of the paths of individual axons across the tectum. Figure 9 illustrates axons which grew around the tectum on opposite sides but are clearly intermingled at the caudal edge of the tectum. These are axons which had recently grown into the tectum and, thus, had done little shifting. Figure 11 shows axons which all terminate in the same region of the terminal zone but have had rather varied paths over the last several hundred micrometers in reach- ing this zone. One axon (arrowhead) even made a $360^{\circ}$ loop before continuing on to its termination. Yet it still reached the appropriate termination zone. These axons are terminating on central, rostral tectum so presumably the paths shown here are actually the secondary trajectories of these axons after considerable shifting across the tectal surface. Thus, axons appear to take varied routes both to get to their initial sites of termination and as they shift across the tectal surface. Clearly, axons need not obey strict mechanical guidance rules, at least in their paths near the synaptic zone.

One of the problems with anatomical studies is that they are always open to the criticism that aberrantappearing structures or axons may not be functional. While this criticism is always valid, the ability to visualize the terminals and to know that they are in the appropriate region of the tectum and are with the terminals from other ganglion cells in that part of the retina provides strong evidence that these axons found their correct sites for termination even though they did not follow identical paths to get there.

In conclusion, the paths of axons shown here suggest that axons use a number of different mechanisms to guide them to their correct terminal sites in the tectum. Whenever possible, axons appear to grow along the easiest path available, the surface created by earlier axons. This surface guides axons from one end of the nerve to the other without significantly jumbling them, and on the tectal surface it forces them to grow near the peripheral synaptic zone where they will synapse rather than on parts of the tectal surface which are occupied by much older axons and have no appropriate synaptic sites for any of the ingrowing axons. Additionally, this growth pattern prevents ingrowing axons from having access to inappropriate central termination sites which might be temporarily vacated by shifting central axons. At other points in their paths the axons appear to respond to more complex cues than simple mechanical guidance. Before the bifurcation of the optic tract, they appear to sort and rearrange themselves. Axons which terminate rostrally find some cue which tells them to force terminals already occupying the available synaptic space to move. In turn, this movement sets off a chain reaction of shifting terminals which serves to maintain an appropriately centered retinotopic map on the tectum.

Individual axons appear to be able to sort among themselves and find appropriate neighbors and/or termination sites so that they are not necessarily stuck with their growing partners as perpetual neighbors. Thus, axons appear to use paths which minimize the need for them to make choices, but at certain points these paths contain insufficient information and then other more complex cues are used by axons to find correct sites for termination.

Note added in proof. A more complete description of the model of Easter and Stuermer has recently appeared (Easter and Stuermer, 1984).

\section{References}

Anders, J. J., and E. Hibbard (1974) The optic system of the teleost Cichlasoma biocellatum. J. Comp. Neurol. 158: 145154. 
Bodick, N., and C. Levinthal (1980) Growing optic fibers follow neighbors during embryogenesis. Proc. Natl. Acad. Sci. U. S. A. $77: 4374-4378$.

Bunt, S. M. (1982) Retinotopic and temporal organization of the optic nerve and tracts in the adult goldfish. J. Comp. Neurol. 206: 209-226.

Bunt, S. M., and T. J. Horder (1978) Evidence for an orderly arrangement of optic axons in the central pathways of vertebrates and its implications for the formation and regeneration of optic projections. Soc. Neurosci. Abstr. 4: 468.

Bunt, S. M., and T. J. Horder (1983) Evidence for an orderly arrangement of optic axons within the optic nerve of the major non-mammalian vertebrate classes. J. Comp. Neurol. 213: 94-114.

Bunt, S. M., T. J. Horder, and K. A. C. Martin (1979) The nature of the nerve fibre guidance mechanism responsible for the formation of an orderly central visual projection. NATO Adv. Study Ser. A 27: 331-343.

Chung, S. H., M. J. Keating, and T. V. P. Bliss (1974) Functional synaptic relations during the development of the retino-tectal projections in amphibians. Proc. R. Soc. Lond. (Biol.) 187: 449-459.

Cima, C. (1979) An ultrastructural morphometric analysis of the organization of the developing optic nerve of Xenopus laevis. Soc. Neurosci. Abstr. 5: 156.

Constantine-Paton, M. (1982) The retinotectal hookup: The process of neural mapping. In Developmental Order: Its Origin and Regulation, pp. 317-349, Alan R. Liss, Inc., New York.

Easter, S. S., Jr., and C. A. O. Stuermer (1982) Evidence for naturally occurring movements of retinotectal terminals in goldfish. Soc. Neurosci. Abstr. 8: 745.

Easter, S. S., Jr., and C. A. O. Stuermer (1984) An evaluation of the hypothesis of shifting terminals in goldfish optic tectum. J. Neurosci. 4 1052-1063.

Easter, S. S., Jr., P. E. Kish, and S. S. Scherer (1979) Growth and development of the optic nerve in juvenile goldfish. Soc. Neurosci. Abstr. 5: 158.

Easter, S. S., Jr., A. C. Rusoff, and P. E. Kish (1981) The growth and organization of the optic nerve and tract in juvenile and adult goldfish. J. Neurosci. 1: 793-811.

Greenwood, P. H., D. E. Rosen, S. H. Weitzman, and G. S. Myers (1966) Phyletic studies of teleostean fishes, with a provisional classification of living forms. Bull. Am. Museum Nat. Hist. 131: $339-455$.

Horder, T. J., and K. A. C. Martin (1978) Morphogenetics as an alternative to chemospecificity in the formation of nerve connections. In Cell-Cell Recognition, A. S. G. Curtis, ed., pp. 275-358, Cambridge University Press, Cambridge.

Johns, P. R. (1977) Growth of the adult goldfish eye. III. Source of the new retinal cells. J. Comp. Neurol. 176: 343-358.

Johns, P. R. (1981) Growth of fish retinas. Am. Zool. 21: 447458.

Kock, J. -H. and T. Reuter (1978) Retinal ganglion cells in the crucian carp (C. carassius). I. Size and number of somata in eyes of different size. J. Comp. Neurol. 179: 535-548.

Lam, K., A. J. Sefton, and M. R. Bennett (1982) Loss of axons from the optic nerve of the rat during early postnatal development. Dev. Brain Res. 3: 487- 491.

Leghissa, S. (1955) La struttura microscopica e la citoarchitettonica del tetto ottico dei pesci teleostei. Z. Anat. Entwicklungsgesch. 118: 427-463.

Meyer, R. L. (1978) Evidence from thymidine labeling for continuing growth of retina and tectum in juvenile goldfish. Exp. Neurol. 59: 99-111.

Müller, H. (1952) Bau und Wachstum der Netzhaut des Guppy (Lebistes reticulatus). Zool. Jb. 63: 275-324.

$\mathrm{Ng}$, A. Y. K., and J. Stone (1982) The optic nerve of the cat: Appearance and loss of axons during normal development. Dev. Brain Res. 5: 263-271.

Rakic, P., and K. P. Riley (1983) Overproduction and elimination of retinal axons in the fetal rhesus monkey. Science 219: 1441-1444.

Raymond, P. A., and S. S. Easter, Jr. (1983) Postembryonic growth of the optic tectum in goldfish. I. Location of germinal cells and numbers of neurons produced. J. Neurosci. 3: 10771091.

Rusoff, A. C. (1980) Paths of optic axons across the tectum of fish. Invest. Ophthalmol. Vis. Sci. (Suppl.) 18: 2.

Scholes, J. H. (1979) Nerve fibre topography in the retinal projection to the tectum. Nature 278: 620-624.

Straznicky, K., and R. M. Gaze (1972) The development of the tectum in Xenopus laevis: An autoradiographic study. J. Embryol. Exp. Morphol. 28: 87-115.

Studnička, F. K. (1897) Untersuchungen uber den Bau des Sehnerven der Wirbeltiere. Jena. Z. Naturwiss. 31: 1-28. 